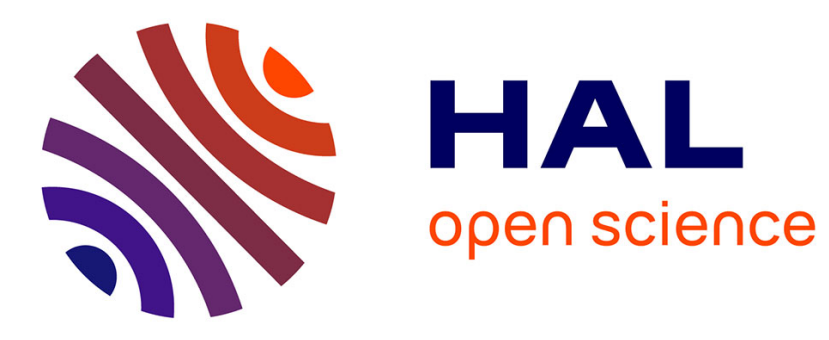

\title{
Probing consciousness in a sensory-disconnected paralyzed patient
}

Benjamin Rohaut, Federico Raimondo, Damien Galanaud, Mélanie Valente, Jacobo Diego Sitt, Lionel Naccache

\section{- To cite this version:}

Benjamin Rohaut, Federico Raimondo, Damien Galanaud, Mélanie Valente, Jacobo Diego Sitt, et al.. Probing consciousness in a sensory-disconnected paralyzed patient. Brain Injury, 2017, pp.1-6. 10.1080/02699052.2017.1327673 . hal-01558164

\section{HAL Id: hal-01558164 https://hal.sorbonne-universite.fr/hal-01558164}

Submitted on 7 Jul 2017

HAL is a multi-disciplinary open access archive for the deposit and dissemination of scientific research documents, whether they are published or not. The documents may come from teaching and research institutions in France or abroad, or from public or private research centers.
L'archive ouverte pluridisciplinaire HAL, est destinée au dépôt et à la diffusion de documents scientifiques de niveau recherche, publiés ou non, émanant des établissements d'enseignement et de recherche français ou étrangers, des laboratoires publics ou privés. 


\section{Probing consciousness in a sensory-disconnected}

\section{paralyzed patient}

Benjamin Rohaut ${ }^{\mathrm{a}, \mathrm{b}, \mathrm{c}, \mathrm{d}, \mathrm{e}}{ }^{*}$, Federico Raimondo ${ }^{\mathrm{b}, \mathrm{c}, \mathrm{f,g}}{ }^{*}$, Damien Galanaud ${ }^{\mathrm{d}, \mathrm{h}}$,

Mélanie Valente ${ }^{b, c}$, Jacobo Diego Sitt ${ }^{b, c}$, and Lionel Naccache $e^{b, c, d, i}$.

a) Department of Neurology, AP-HP, Groupe hospitalier Pitié-Salpêtrière, Neuro-ICU, Paris, France

b) INSERM, U 1127, Paris, France

c) Institut du Cerveau et de la Moelle épinière, ICM, PICNIC Lab, Paris, France

d) Faculté de Médecine Pitié-Salpêtrière, Sorbonne Universités, UPMC Univ Paris 06, Paris, France

e) Department of Neurology, Neuro-ICU, Columbia University, New York, US

f) Laboratorio de Inteligencia Artificial Aplicada, Departamento de Computación, FCEyN, Universidad de Buenos Aires, Argentina.

g) CONICET, Argentina

h) Department of Neuroradiology, AP-HP, Groupe hospitalier Pitié-Salpêtrière, Paris, France

i) Department of Neurophysiology, AP-HP, Groupe hospitalier Pitié-Salpêtrière, Paris, France

* Benjamin Rohaut and Federico Raimondo contributed equally to this work.

\section{Corresponding author:}

Benjamin Rohaut

benjamin.rohaut@gmx.com

Division of Critical Care \& Hospitalist Neurology, Columbia University Medical Center, 177 Fort Washington Avenue, MHB 8 Center, Room 300, New York, NY 10032.

Keywords: disorder of consciousness; quantitative EEG; brain functional imagery; consciousness; locked-in syndrome. 


\section{Abstract:}

Background: Diagnosis of consciousness can be very challenging in some clinical situations such as severe sensory-motor impairments.

Case study: We report the case study of a patient who presented a total "locked-in syndrome" associated with and a multi-sensory deafferentation (visual, auditory and tactile modalities) following a protuberantial infarction.

Result: In spite of this severe and extreme disconnection from the external world, we could detect reliable evidence of consciousness using a multivariate analysis of his high-density resting state electroencephalogram. This EEG-based diagnosis was eventually confirmed by the clinical evolution of the patient.

Conclusion: This approach illustrates the potential importance of functional brainimaging data to improve diagnosis of consciousness and of cognitive abilities in critical situations in which the behavioral channel is compromised such as deafferented locked-in syndrome. 


\section{Introduction}

Diagnosis of consciousness can be very challenging in some clinical situations such as severe sensory-motor or cognitive impairments ${ }^{[1]}$. When patients can neither communicate (verbally or non-verbally) nor exhibit any intentional behavior, clinicians have to rely on indirect cues collected through behavioral and functional brain-imaging methods ${ }^{[2]}$. During the last decade, several cognitively active tasks have been developed in this perspective while recording brain activity with fMRI or bedside EEG. For instance, putative neural signatures of conscious processing have been identified by asking a patient to perform a mental imagery task ${ }^{[3,4]}$ or an explicit mental counting of rare stimuli delivered among frequent ones ${ }^{[5,6]}$. However, each of this measures require the patient to receive and perceive task instructions. Obviously, a sensory disconnected brain challenges this original approach given the impossibility to deliver instructions to the patient. In the present case study, we report how we could convincingly identify EEG neural signatures of consciousness in such a "sensory disconnected" and paralyzed patient.

\section{Case study}

The patient was 63 years old when he suffered from a brainstem infarction following a scheduled abdominal surgery that subsequently raised the question of the diagnosis of a locked-in syndrome. He had several medical conditions including arrhythmic cardiopathy, inherited thrombotic factor (factor V Leiden mutation), hypertension, dyslipidemia, atherosclerosis and a chronic renal disease which required kidney transplantation 3 years ago. After surgery (scheduled colic continuity reestablishment surgery following a Hartmann surgery for an acute colitis), the patient suffered from a 
septic shock. Sedation was maintained at the minimum level and duration following international guidelines ${ }^{[7]}$ and stopped after four days. Although the patient recovered wakefulness, he remained unable to express any intentional behaviour. MRI revealed an infarction of the median and transversal bulbo-protuberantial territory in relation with a basilar artery occlusion (Figure 1; Figure S1-B). Neurological examination revealed a spontaneous ocular bobbing (Video S1) with no visual pursuit, no blink to visual threat, and no startle reflex to loud noise. Pupillary light reflexes, corneal and cough reflexes were preserved. The patient did not show any movement of the limbs or of the face, even after nociceptive stimulation. According to the current behavioural and clinical scores, this patient was classified as being in a vegetative state/unresponsive wakefulness syndrome (VS/UWS; Table 1). This mismatch between a radiological pattern reminiscent of locked-in syndrome, and a much poorer behavioural evidence of conscious processing triggered the decision to transfer the patient to our "Disorders of Consciousness patients Team" two months after the diagnosis of the brainstem infraction.

\section{Beyond behavior}

A quantitative MRI analysis of the supra-tentorial white matter fractional anisotropy

${ }^{[8]}$ revealed a normal pattern, and therefore invalidated the hypothesis of a per-surgery or post-surgery shock - related severe brain hypoperfusion (Figure 1, Figure S1-A).

Brainstem auditory evoked potentials (BAEP) revealed a severe peripheral and central deafness with a bilateral alteration of wave-I and III (110dB stimulation level) and the abolition of wave- $\mathrm{V}$. This pattern explained the absence of startle reflex, and the potential inability to understand verbal commands. The auditory deficit resulted from the association of an otitis media, a cochlear dysfunction related to tacrolimus toxicity, and a possible VIIIth nucleus and intra-axial VIIIth nerve lesions (Figure 1). 
We did not find any cerebral responses elicited by the auditory 'Local Global' evoked-related potentials paradigm. This paradigm developed by our team is usually able to probe neural signature of conscious processing in patients ${ }^{[5,6,9]}$. However, in this case, the patient's deafness prevented a reliable interpretation of this negative result. SSEP revealed a preservation of bulbar responses (N14 and N18), but a severe alteration of cortical responses (abolition of N20 on the left side and severe alteration on the right side).

EEG background activity, - recorded at bedside with 8 electrodes -, consisted in a posterior and symmetrical theta band $(4-6 \mathrm{~Hz})$ activity, slightly reactive to passive eye-opening/closing, but neither to auditory nor to nociceptive stimulation.

At this stage, we hypothesized that the patient was indeed in a particular form of locked-in syndrome (also called deefferentation syndrome) since associated with deafness and severe visual impairment that could be called a "deafferented locked-in syndrome". Several attempts to deliver the patient with visual written instructions (asking to move his eyes) failed. However, the absence of horizontal eye mobility as well as the permanent bobbing could not rule out a patient's inability to accurately read verbal commands.

To overcome this severe multi-sensory disconnection, we used an automatic classification algorithm we recently designed and trained to distinguish between VS/UWS and minimally conscious state (MCS) patients on the basis of a high-density EEG recording while stimulated under an auditory oddball paradigm ${ }^{[10,11]}$. This classifier combines several tens of putative EEG markers sensitive to conscious states such as event related potentials, signal complexity, long-range functional connectivity and spectral power patterns. Although the patient was deaf and thus, the event related potentials were absent, our classifier considered this patient as being most likely in a 
condition of minimally or conscious state $(71 \%)$, while a VS/UWS could not be ruled out $(29 \%)$. We then analyzed in detail the univariate markers that are usually more contributive to the multivariate classifier by comparing the topographies from the previously recorded and diagnosed patients with this patient. Detailed analysis further revealed that patterns of spectral power of EEG (in delta and alpha band), complexity markers (spectral entropy, permutation entropy and Komolgorov-Chaitin complexity), and functional connectivity (weighted Symbolic Mutual Information, wSMI ${ }^{[12]}$ ) were strongly supportive of a conscious state, rather than of a VS/UWS or even MCS (Figure 2). As expected, univariate markers of auditory event-related potentials were not contributive given patient's deafness.

In summary, anatomical and electrophysiological brain data supported a diagnosis of "extreme locked-in syndrome" with major motor and multi-sensory deficits. After a week of systematical attempts to deliver visual instructions, - strongly encouraged by the results of our exploration supporting consciousness -, we eventually could observe a reproducible visual pursuit of a mirror, and then of any vertically moving target (bobbing was still present and vertical oculocephalic reflex still abolished suggesting a vestibular input impairment). According to this visual pursuit behaviour, the patient was now scored as MCS on the CRS-R ${ }^{[13]}$. However, and in spite of our efforts, the patient could not follow written commands (see Video S2). Three weeks after patient admission (one week after high-density EEG recording), we could finally detect a more complex behaviour: in response to a big contrasted arrow pointing either upward or downward, the patient was able to systematically orient his gaze toward the direction pointed by the arrow (see Video S3). These responses strongly suggested that the patient was able: i) to engage attention, ii) to understand the meaning of this symbol, iii) to use it as a cue to elicit an intentional behaviour meaningful for the 
examiner, and iv) to actively maintain this intentional behaviour during long periods of time (tens of seconds). These characteristics are generally indicative of conscious behaviours ${ }^{[14]}$.

\section{Discussion}

This case study demonstrates the utility of functional brain-imaging (here EEG), - in complement to detailed clinical, behavioural and structural imaging data -, to probe consciousness and cognition in such an extreme condition of severe motor and multisensory disconnection. In contrast to more classical approaches previously reported ${ }^{[3,15-19]}$, because of his massive sensory impairment, we could not use any task instruction or stimulus processing correlates to probe consciousness in this patient. The ability of automatized and quantitative EEG-based mathematical classifiers to capture putative markers of consciousness in the absence of any behavioural evidence and of sensory-motor pathway impairment is of potentially great importance. In the present case, our algorithm preceded behavioural evidence of consciousness by 7 days. Finally, preliminary reanalysis of our database showed that all these markers could also be computed from a standard bedside 21-electrodes EEG and provide very similar results (submitted). If confirmed, this method could be nicely complete the TMS/EEG method ${ }^{[20]}$, which is also able to probe consciousness while bypassing the sensory-motor pathway, but needs a very highly complex acquisition setting.

\section{Materiel and methods}

The patient EEG was recorded in the very same condition as our patients' database ${ }^{[10]}$ while being subject to the Local-Global paradigm ${ }^{[5]}$. Briefly, the Local-Global paradigm is characterized by two embedded levels of auditory regularities allowing to 
identify the cortical response to sounds (P1), the automatic response to local novelty (MMN and P3a) and the conscious response to global novelty (P3b).

EEG was sampled at $250 \mathrm{~Hz}$ with a 256-electrode geodesic sensor net connected to a high impendence amplifier (EGI, Oregon, US) referenced to the vertex. Impedances were controlled inferior to $100 \mathrm{k} \Omega$. Data were filtered from $0.5 \mathrm{~Hz}$ to $45 \mathrm{~Hz}$. Trials were segmented from $-200 \mathrm{~ms}$ to $1300 \mathrm{~ms}$ relative to the onset of the Local-Global trials. Electrodes in which more than $50 \%$ of the trails exceeded a $100 \mu \mathrm{V}$ were marked for rejection. Trials were at least $10 \%$ of the electrodes exceeded the same threshold were discarded. Data was re-referenced to the average of all electrodes. Finally, electrodes marked for rejection were discarded and the information was reconstructed using interpolation.

Markers were then computed as described in the original publication supplementary material $^{[10]}$.

Structural Similarity Index Measure (SSIM) was computed according to the original formula ${ }^{[21]}$ with modifications to apply it on EEG topographies: each electrode was assumed to be a pixel. Since the EEG montage is three-dimensional, the definition of neighbours was redefined as all the electrodes within an Euclidean norm of 1.0 from a normalized montage between -1.0 and 1.0 in all axes (X, Y and $\mathrm{Z})$.

All processing stages and topographical maps were performed with MNE-python ${ }^{[22,23]}$ and custom made python libraries. The Case Report guidelines were followed throughout ${ }^{[24]}$. 


\section{Funding:}

This work was supported by Assistance Publique - Hôpitaux de Paris (AP-HP; BR, DG, LN), Institut National de la Santé et de la Recherche Médicale (INSERM; BR, JS, LN), Association Amicale des Anciens Internes en Médecine des Hôpitaux de Paris (AAIHP; BR), Syndicat des Chefs de Clinique \& Assistants des Hôpitaux de Paris (SCCAHP; BR), Philippe Foundation (BR), Consejo Nacional de Investigaciones Científicas y Técnicas (CONICET; FR), Université Pierre et Marie Curie, Paris 6 (UPMC ; DG, LN), the James S. McDonnell Foundation (LN), STICAmSud grants Complexity as a neural marker: applications to EEG and natural language processing and RTBRAIN - Towards Real-time processing of brain signals (FR, JS) and Académie des Sciences - Grand Prix Lamonica de Neurologie (LN). All the authors report no declarations of interest.

\section{Patient Consent:}

Authors have received the patient 'spouse written consent for this publication.

However, as the patient's consent could not be obtained, details have been removed from this case description to ensure a maximal anonymity.

\section{Acknowledgement:}

We thank the patient's spouse to have kindly agreed that we report this case study. We also thank Dr Francis Bolgert, Dr. Sophie Demeret, Dr. Athena Demertzi, Dr Caline El Jadam, Dr. Frédéric Faugeras, Prof. Diego Fernandez Slezak, Dr. Arnaud 
Follin, Dr. Bertrand Gaymard, Dr. Jean-Remi King, Dr. Régine Morizo-Koutlidis and Dr Marion Quirins for their help in this case study. 


\section{References:}

[1] Rohaut B, Faugeras F, Naccache L. Neurology of consciousness impairments. In: Stevens RD, Sharshar T and Ely EW (eds), Brain Disorders in Critical Illness: Cambridge, UK: Cambridge University Press, 2013.

[2] Giacino JT, Fins JJ, Laureys S, Schiff ND. Disorders of consciousness after acquired brain injury: the state of the science. Nature reviews Neurology Neurology. 2014;10(2):99-114.

[3] Owen AM, Owen AM, Coleman MR, Coleman MR, Boly M, Boly M, Davis MH, Davis MH, Laureys S, Laureys S, et al. Detecting Awareness in the Vegetative State. Science. 2006;313(September):2006-2006.

[4] Cruse D, Chennu S, Chatelle C, Bekinschtein TA, Fernández-Espejo D, Pickard JD, Laureys S, Owen AM. Bedside detection of awareness in the vegetative state: a cohort study. Lancet. 2011;378(9809):2088-2094.

[5] Bekinschtein TA, Dehaene S, Rohaut B, Tadel F, Cohen L, Naccache L. Neural signature of the conscious processing of auditory regularities. Proceedings of the National Academy of Sciences. 2009;106(5):1672-1677.

[6] Faugeras F, Rohaut B, Weiss N, Bekinschtein TA, Galanaud D, Puybasset L, Bolgert F, Sergent C, Cohen L, Dehaene S, et al. Probing consciousness with event-related potentials in the vegetative state. Neurology. 2011;77(3):264-268.

[7] Barr J, Fraser GL, Puntillo K, Ely EW, Gélinas C, Dasta JF, Davidson JE, Devlin JW, Kress JP, Jofe AM, et al. Clinical practice guidelines for the management of pain, agitation, and delirium in adult patients in the intensive care unit: Executive summary. American Journal of Health-System Pharmacy. 2013;70(1):53-58.

[8] Luyt C-E, Galanaud D, Perlbarg V, Vanhaudenhuyse A, Stevens RD, Gupta R, Besancenot H, Krainik A, Audibert G, Combes A, et al. Diffusion tensor imaging 
to predict long-term outcome after cardiac arrest: a bicentric pilot study.

Anesthesiology. 2012;117(6):1311-21.

[9] Faugeras F, Rohaut B, Weiss N, Bekinschtein T, Galanaud D, Puybasset L, Bolgert F, Sergent C, Cohen L, Dehaene S, et al. Event related potentials elicited by violations of auditory regularities in patients with impaired consciousness. Neuropsychologia. 2012;50(3):403-418.

[10] Sitt JD, King JR, El Karoui I, Rohaut B, Faugeras F, Gramfort A, Cohen L, Sigman M, Dehaene S, Naccache L. Large scale screening of neural signatures of consciousness in patients in a vegetative or minimally conscious state. Brain. 2014;137(8):2258-2270.

[11] Engemann D, Raimondo F, King J-R, Jas M, Gramfort A, Dehaene S, Naccache L, Sitt J. Automated Measurement and Prediction of Consciousness in Vegetative and Minimally Conscious Patients. ICML Workshop on Statistics, Machine Learning and Neuroscience (Stamlins 2015). 2015.

[12] King JR, Sitt JD, Faugeras F, Rohaut B, El Karoui I, Cohen L, Naccache L, Dehaene S. Information sharing in the brain indexes consciousness in noncommunicative patients. Current Biology. 2013;23(19):1914-1919.

[13] Giacino JT, Kalmar K, Whyte J. The JFK Coma Recovery Scale-Revised: Measurement characteristics and diagnostic utility. Archives of Physical Medicine and Rehabilitation. 2004;85(12):2020-2029.

[14] Dehaene S, Changeux JP, Naccache L, Sackur J, Sergent C. Conscious, preconscious, and subliminal processing: a testable taxonomy. Trends in Cognitive Sciences. 2006;10(5):204-211.

[15] Carrai R, Grippo A, Fossi S, Campolo MC, Lanzo G, Pinto F, Amantini A. Transient post-traumatic locked-in syndrome: A case report and a literature review. Neurophysiologie Clinique. 2009;39(2). 
[16] Schnakers C, Perrin F, Schabus M, Hustinx R, Majerus S, Moonen G, Boly M, Vanhaudenhuyse A, Bruno M-A, Laureys S. Detecting consciousness in a total locked-in syndrome: an active event-related paradigm. Neurocase. 2009; 15(4):271-7.

[17] John ER, Halper JP, Lowe RS, Merkin H, Defina P, Prichep LS. Source imaging of QEEG as a method to detect awareness in a person in vegetative state. Brain injury. 2011 [accessed 2017 Mar 29];25(4):426-32. http://www.tandfonline.com/doi/full/10.3109/02699052.2011.558045

[18] Pistoia F, Carolei A, Iacoviello D, Petracca A, Sacco S, Sarà M, Spezialetti M, Placidi G. EEG-detected olfactory imagery to reveal covert consciousness in minimally conscious state. Brain injury. 2015 [accessed 2017 Mar 29];29(1314):1729-35. http://www.tandfonline.com/doi/full/10.3109/02699052.2015.1075251

[19] Aslaksen PM, Vangberg TR, Schäfer C. Probing for consciousness after severe brain injury by functional magnetic resonance imaging (fMRI). Journal of neurology. 2012 [accessed 2017 Mar 29];259(3):576-8. http://link.springer.com/10.1007/s00415-011-6223-6

[20] Rosanova M, Gosseries O, Casarotto S, Boly M, Casali AG, Bruno MA, Mariotti M, Boveroux P, Tononi G, Laureys S, et al. Recovery of cortical effective connectivity and recovery of consciousness in vegetative patients. Brain. 2012;135(4):1308-1320.

[21] Wang Z, Bovik AC, Sheikh HR, Simoncelli EP. Image quality assessment: From error visibility to structural similarity. IEEE Transactions on Image Processing. 2004;13(4):600-612.

[22] Gramfort A, Luessi M, Larson E, Engemann DA, Strohmeier D, Brodbeck C, Goj R, Jas M, Brooks T, Parkkonen L, et al. MEG and EEG data analysis with 
MNE-Python. Frontiers in Neuroscience. 2013;7:267.

[23] Gramfort A, Luessi M, Larson E, Engemann DA, Strohmeier D, Brodbeck C, Parkkonen L, Hämäläinen MS. MNE software for processing MEG and EEG data. NeuroImage. 2014;86:446-460.

[24] Gagnier JJ, Kienle G, Altman DG, Moher D, Sox H, Riley D. The CARE Guidelines: Consensus-based Clinical Case Reporting Guideline Development. Global Advances in Health and Medicine. 2013;2(5):38-43. 


\section{Figures' legend:}

Figure 1. MRI in sagittal T1-weigthed (A) and axial T2-weighted acquisitions (B,

C). There is a localized ischemic lesion at the upper part of the medulla oblongata and lower part of the pons, including the cortico spinal tracks and nuclei of the VIIIth nerves. Bilateral filling of the mastoids and middle ears and small ischemic infarction of the right cerebellar hemisphere are also present.

Figure 2. Topographical map of the patient's EEG markers. Scalp topographical $2 \mathrm{D}$ projection $($ top $=$ front $)$ of each measure [contingent negative variation $(\mathrm{CNV})$, mismatch negativity $(\mathrm{MMN}), \mathrm{P} 300 \mathrm{~b}(\mathrm{P} 3 \mathrm{~B})$, normalized power in delta $(\| \delta||)$ and alpha $(\|\boldsymbol{\alpha}\|)$ bands, spectral entropy (SE), permutation entropy in theta band (PE $\boldsymbol{\theta}$ ), Komolgorov-Chaitin Complexity (K) and weighted symbolic mutual information in theta band (wSMI $\boldsymbol{\theta})$ ] obtained from the patient's EEG (first column, "Patient"). These topographies were compared to groups of Vegetative State /Unresponsive Wakefulness Syndrome (VS/UWS: n=76), Minimally Conscious State (MCS; n=68) and Conscious State patients $(\mathrm{CS} ; \mathrm{n}=23)$ as well as Healthy controls $(\mathrm{H} ; \mathrm{n}=14)$. The last column shows the topographical similarity of patient's topography compared to each of the groups (SSIM; z-score $+/-95 \% \mathrm{CI}$ ). 


\section{Supplementary Online Material:}

Figure S1. Sagittal reconstructed FA map derived from diffusion tensor imaging (A) and angio MR acquisition of the circle of Willis (B). There is an interruption of the corticospinal track at the junction between the pons and the medulla oblongata (white arrow). The angio MRI discloses a persistent occlusion of the basilar artery at this level, with recirculation in its upper part through the posterior communicating arteries.

Video S1. Clinical examination revealed spontaneous vertical eyes movement (downward fast movement) corresponding to an eye bobbing. Horizontal and vertical oculocephalic reflexes were abolished.

Video S2. After several attempts, the patient became able to follow visual targets moving vertically (day 16). In this video we used a mirror, as visual pursuit of one's own gaze has been shown to be one of the most efficient visual target.

Video S3. The patient became able to follow symbolic instructions delivered implicitly through a large arrow drawn on a slate pointing downward or upward (day 20). The short reaction time and the consistency (12 successive trials with a $100 \%$ accuracy in this video) of this behaviour were in favour of intentional conscious behaviour (see text for discussion of this issue). 
Table 1. Clinical scores across time.

\begin{tabular}{|c|c|c|c|c|c|c|c|c|c|c|}
\hline Day & D1 & D1 ${ }^{*}$ & D2 & D6 & $\mathrm{D} 13^{* / * *}$ & D16 & D16 ${ }^{*}$ & D18 & D19 & D20* \\
\hline \multicolumn{11}{|l|}{$\begin{array}{l}\text { Coma Recovery } \\
\text { Scale (CRS-R) }\end{array}$} \\
\hline Auditory & & 0 & & & 0 & & 0 & & & 0 \\
\hline Visual & & 2 & & & 2 & & 4 & & & 4 \\
\hline Motor & & 0 & & & 2 & & 2 & & & 2 \\
\hline Oromotor/verbal & & 0 & & & 0 & & 0 & & & 0 \\
\hline Communication & & 0 & & & 0 & & 0 & & & 0 \\
\hline Arousal & & 1 & & & 1 & & 1 & & & 1 \\
\hline Total & & 3 & & & 5 & & 7 & & & 7 \\
\hline \multicolumn{11}{|l|}{ FOUR-Score } \\
\hline Eye response & 0 & 3 & 0 & 0 & 0 & 0 & 4 & 0 & 2 & 4 \\
\hline Motor response & 0 & 0 & 2 & 2 & 2 & 2 & 2 & 2 & 2 & 2 \\
\hline Brainstem reflexes & 4 & 4 & 4 & 4 & 4 & 4 & 4 & 4 & 4 & 4 \\
\hline Respiration & 1 & 0 & 1 & 1 & 1 & 0 & 1 & 1 & 1 & 1 \\
\hline Total & 5 & 7 & 7 & 7 & 7 & 6 & 11 & 7 & 9 & 11 \\
\hline \multicolumn{11}{|l|}{$\begin{array}{l}\text { Glasgow Coma } \\
\text { Scale }\end{array}$} \\
\hline Eye response & 1 & 4 & 1 & 1 & 1 & 1 & 3 & 1 & 2 & 4 \\
\hline Motor response & 1 & 1 & 3 & 3 & 3 & 3 & 3 & 3 & 3 & 3 \\
\hline Verbal response & 1 & 1 & 1 & 1 & 1 & 1 & 1 & 1 & 1 & 1 \\
\hline Total & 3 & 6 & 5 & 5 & 5 & 5 & 7 & 5 & 6 & 8 \\
\hline $\begin{array}{l}\text { Clinical } \\
\text { classification }\end{array}$ & Coma & /S/UWS & Coma & Coma & Coma & Coma & MCS & Coma & VS/UWS & $\operatorname{CS}^{\pi \times x}$ \\
\hline
\end{tabular}

Clinical scores obtained 2 months after the diagnosis of the brainstem infraction in our unit from day 1 (D1) to day 20 (D20). CRS-R: Coma Recovery Scale - Revised; FOUR-score: Full Outline Of Unresponsiveness; GCS: Glasgow Coma scale obtained during the 20 days observation span.

* Specialized medical examination $(\mathrm{BR}, \mathrm{LN})$; ** ERP; *** Based on the arrow command following, according to the CRS-R the patient was MCS (see Video S3); VS/UWS: Vegetative State/Unresponsive Wakefulness Syndrome; MCS: Minimally Conscious State; CS: Conscious State; FOUR: Full Outline of Unresponsiveness; CRS-R: Coma Recovery Scale - Revised. 


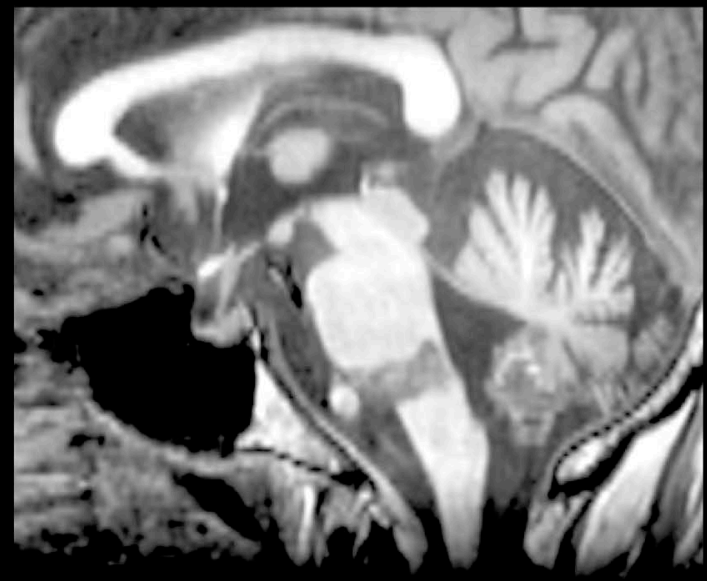

A
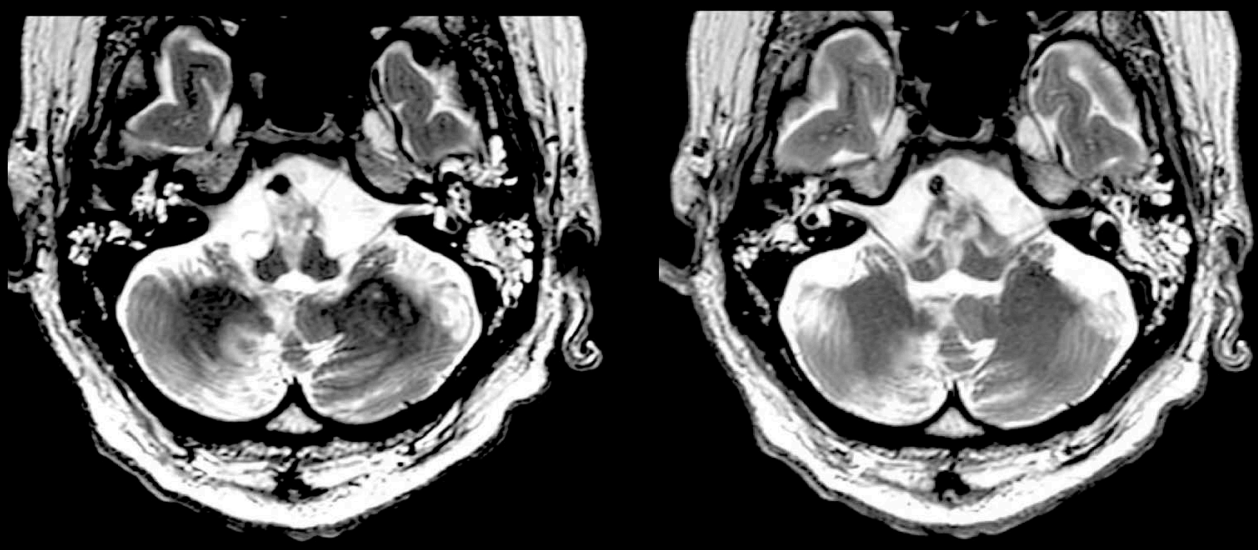

B

C 

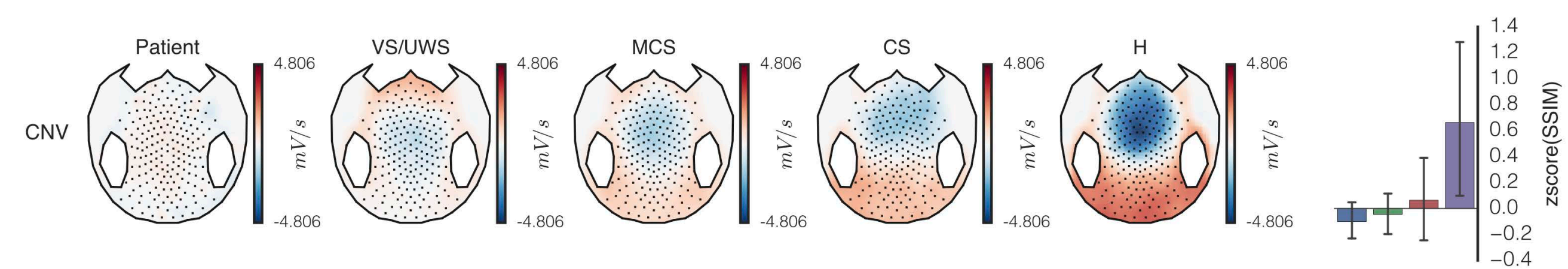

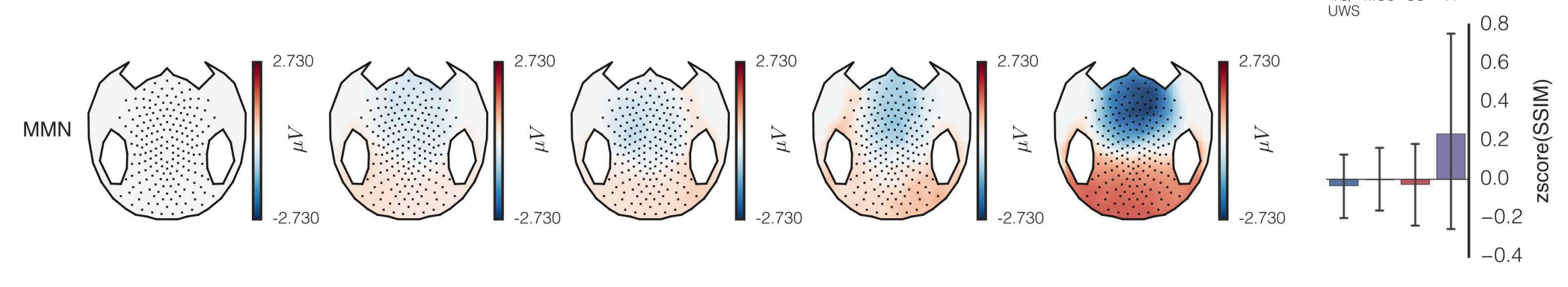

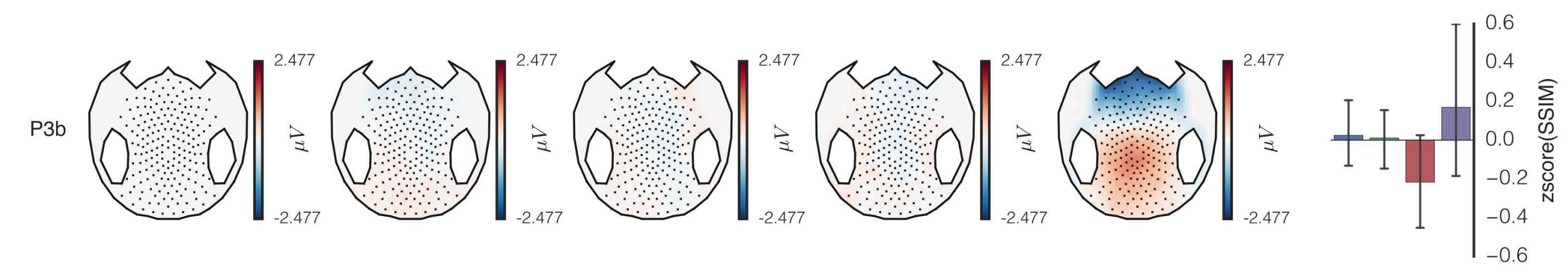

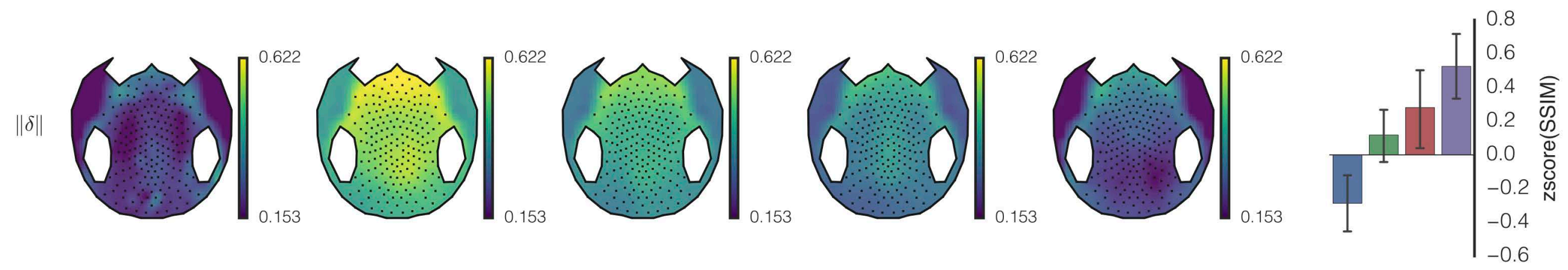

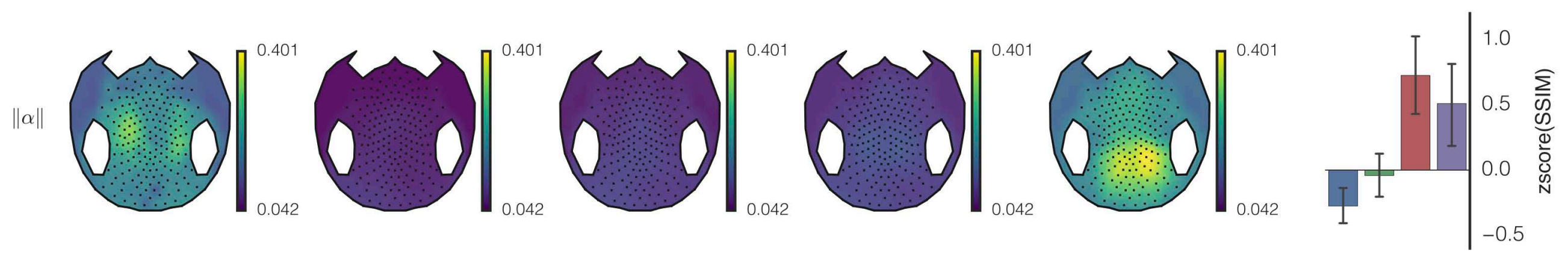

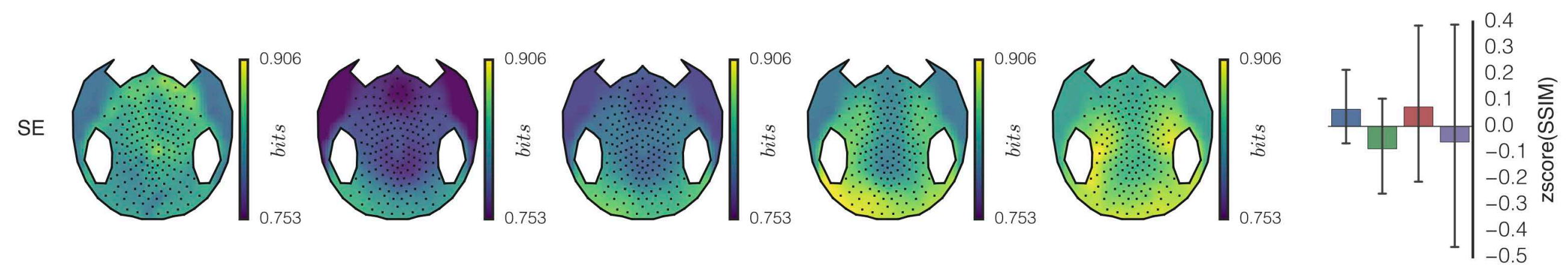

Co: C C

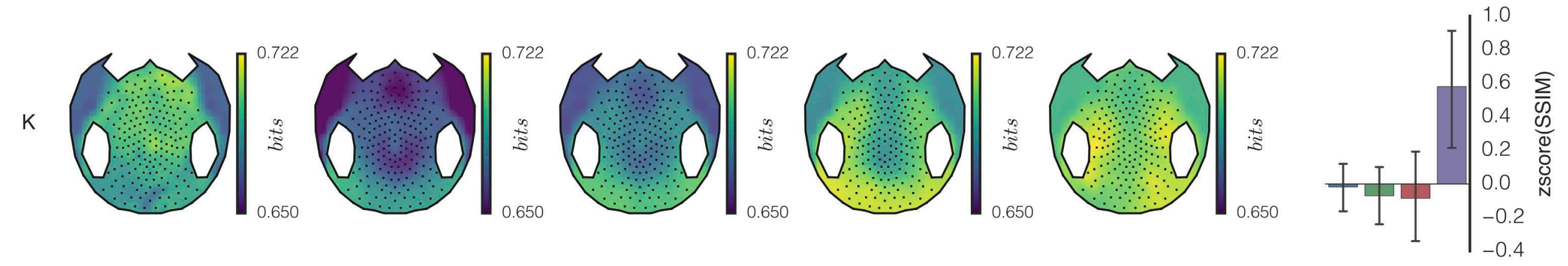

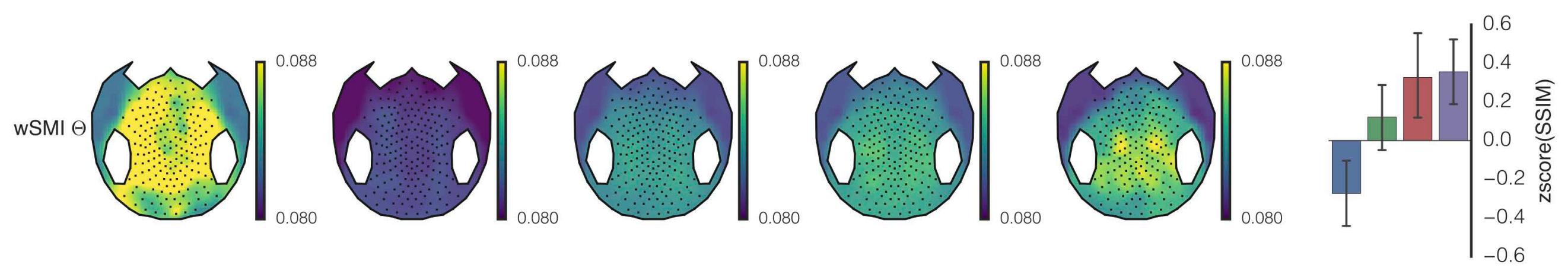

